\title{
IATROGENIA DO CUIDADO DE ENFERMAGEM: DIALOGANDO COM O PERIGO NO QUOTIDIANO PROFISSIONAL*
}

Adriana Ribeiro Martins Madalosso**

MADALOSSO, A.R.M. Iatrogenia do cuidado de enfermagem: dialogando com o perigo no quotidiano profissional. Rev.latino-am.enfermagem, Ribeirão Preto, v. 8, n. 3, p. 11-17, julho 2000.

O artigo apresenta as concepções e experiências de um enfermeiro professor, tecidas no seu quotidiano de cuidar, e desvela, neste contexto, o cuidado iatrogênico de enfermagem. Através da linguagem estética, expõe suas reflexões e alguns referenciais de autores que trabalham o quotidiano, caracterizando o cuidado de enfermagem e, principalmente, o cuidado iatrogênico de enfermagem sob a ótica dos paradigmas modernos e pós-modernos.

UNITERMOS: enfermagem, cuidados de enfermagem, iatrogenia

Neste arranjo de palavras e idéias, estou apresentando meu primeiro exercício de escrever sobre o quotidiano da enfermagem utilizando a linguagem estética. Foi uma tarefa árdua inibir a racionalidade e a objetividade, ainda tão arraigadas no meu ser, e deixar aflorar a criatividade e uma sensibilidade latente, que nem eu própria imaginei possuir. Encontrei inspiração para este início de construção na mensagem de Richard Cushing $\left(\operatorname{SANTOS}^{19}\right.$, p. 160):

Muito talento se perde no mundo pela falta de um pouco de coragem. Todos os dias, são mandados para os seu túmulos homens obscuros, cuja timidez lhes impediu de fazer um primeiro esforço e que, se pudessem ter sido induzidos a começar teriam, muito provavelmente, ido muito longe (...). O fato é que, para realizar no mundo qualquer coisa digna de ser realizada, não devemos ficar para trás, temendo e pensando no frio e no perigo, porém devemos pular e disputar da melhor maneira que pudermos.

Energizei-me com estas idéias e fui a luta para enfrentar esta dupla batalha, de mudar minhas concepções de verdade e de trabalho científico, e de encarar e discutir os perigos inerentes à profissão. Tentei então.

Assim, pela necessidade, pelo desafio e pelo prazer, ousei elencar cenas que revelam um pouco do jogo de viver a enfermagem. Na criação livre, deixei-me a deriva, num mar de idéias e sentimentos, ora torrentes e turbulentos, quase incontroláveis, forçando a prenderme às amarras do compromisso de criar e de experimentar a insegurança, pelo imprevisível e desconhecido; ora, deleitando-me na saborosa calmaria, que me permitiu nadar nas idéias e no prazer de produzir ondas criativas, num admirável encontro comigo própria, com o meu saber e com o meu fazer, o cuidado de enfermagem.

Como enfermeira, interessada nas leituras sensíveis dos fenômenos que desafiam a profissão e o quotidiano, revendo trabalhos instigantes de renomados colegas enfermeiros (LEININGER ${ }^{10}$; COLLIÈRE $^{5,6}$; LEOPARDI $^{11}$; WALDOW et al. ${ }^{20}$; PATRÍCIO ${ }^{15}$; CINCIARULLO $^{1}$; WAIDMAN $^{21}$ ), encontrei o cuidado, como uma característica de envolvimento, de fazer pelo outro, enriquecendo a relação interpessoal e propiciando o desenvolvimento mútuo, dos seres cuidados e dos cuidadores.

Este cuidado que é mais que um fazer, é buscar na ecologia interna do ser humano, a arte de viver em equilíbrio consigo próprio, com os que o rodeiam e com a natureza que lhe ambienta. Mas o quotidiano de cuidar, apesar deste envolvimento e da sustentação científicotécnica que o ampara, muitas vezes estabelece situações que nem sempre são as almejadas. Ao invés de resolvermos os problemas de nosso cliente, somos capazes sim é de gerá-los, e o tão esperado resultado deste cuidado torna-se indesejável. E, foi justamente pensando no meu

\footnotetext{
* Trabalho desenvolvido na discplina Seminário de Controvérsias, do Curso de Mestrado em Assistência de Enfermagem da Universidade Federal de Santa Catarina (UFSC)/Pólo Universidade de Passo Fundo-RS (UPF), 1999

** Professor Assistente II na disciplina de Enfermagem Infando Juvenil, do Curso de Enfermagem da Universidade de Passo Fundo-RS. Mestranda em Assistência de Enfermagem do Curso de Mestrado Interinstitucional da Universidade Federal de Santa Catarina/Pólo UPF-RS
} 
dia a dia de cuidar, como enfermeira professora, ao conhecer os trabalhos de ILLICH $^{9}$ e COHEN $^{2,3,4}$, que encontrei esta figura insólita, negra e assustadora, o cuidado iatrogênico de enfermagem (MADALOSSO ${ }^{13}$ ).

Como professora, deparo-me diariamente, na supervisão dos acadêmicos em atividades práticas, com situações que são inerentes àqueles que estão aprendendo: a inabilidade, a insegurança, a falta de domínio técnico, a limitada capacidade para interpretar e analisar as situações presentes e emergentes, a precipitação, a lentidão, enfim, o maior risco para a falha, para a iatrogenia do cuidado.

Também enfrento riscos, na fragilidade do processo de supervisão. É o professor, o responsável legal pelos atos desempenhados pelos acadêmicos sob sua supervisão, no entanto, um grande número de alunos, o despreparo de alguns deles - seqüela de todo um processo educacional vulnerável -, a complexidade do processo de aquisição de habilidades variadas com e/ou no cliente, e a impossibilidade de supervisionar a todos, em todas as oportunidades ou situações de aprendizagem, aumentam significativamente a possibilidade das situações iatrogênicas, com repercussões importantes para a clientela, para os próprios acadêmicos e para seu supervisor.

Além disto, na convivência quotidiana com os enfermeiros funcionários destes locais de atividade, percebo inúmeras situações que predispõem ao risco de iatrogenia do cuidado de enfermagem: o seu distanciamento das ações que lhe são próprias; a super valorização das atividades gerenciais, determinadas por pressão institucional, desmotivação e/ou desinformação; o seu envolvimento direto e freqüente com tarefas que competem a outros profissionais da equipe de saúde, em detrimento das que lhe são próprias, como por exemplo adequação de dietas, assistência social, intervenções psicológicas, fisioterapia; ausência ou limitação da sistematização e documentação do cuidado de enfermagem; a delegação de cuidados, sem uma supervisão adequada; o distanciamento entre o aprendido na formação acadêmica e o executado na vida profissional; a sobrecarga de serviço paralela ao esvaziamento do cuidado direto à clientela; o não respeito as leis do exercício profissional e uma baixa auto-estima e valorização profissional.

E, voltando-me as múltiplas facetas desta realidade do meu dia a dia, constato ainda, outros fatores que aumentam significativamente a possibilidade de falha: os constantes avanços tecnológicos científicos, tornando cada vez mais complexo e sofisticado o nosso aparato de trabalho; o aperfeiçoamento pessoal necessário a este enfrentamento, não atingindo a mesma velocidade e compatibilidade dos avanços; uma política nacional de saúde corrompida e ultrapassada, conduzido ao sucateamento de todo o sistema.

Por sua vez, a clientela, agente ativo nesta realidade quotidiana, tem se mostrado cada vez mais exigente, crítica e sabedora de seus direitos, buscando o amparo para as situações que não são compatíveis com as ações de saúde desejadas e esperadas. Nas delegacias de defesa do consumidor, órgãos judiciários e conselhos profissionais, são cada vez mais freqüentes os pedidos de esclarecimentos, denúncias, ações e penalizações de instituições e profissionais. Neste ponto, a enfermagem tem se mostrado suscetível, por ser um elo frágil da corrente assistencial de saúde, já que, além das situações que fogem a sua alçada ou a sua intervenção, o próprio profissional tem se predisposto ao risco, negligenciado a sua proteção.

Que figura tão aterrorizante é a iatrogenia? O que ela tem a ver com o fazer da enfermagem?

Revendo a literatura sobre o tema, encontro o termo iatrogenia designando a doença ou enfermidade que resulta de uma ação médica. Tradicionalmente, esta situação assume uma conotação negativa por sua estreita relação com situações de omissão, imperícia, imprudência ou neglicencia.

Mas a iatrogenia é um fenômeno que envolve somente nossos colegas médicos? Como fica a enfermagem neste cenário, considerando que ela atua diretamente com o cliente, por um período bastante prolongado e com um maior número de intervenções que os profissionais médicos?

$\mathrm{O}$ incremento do conhecimento próprio da enfermagem, a valorização e a execução de ações interdependentes às ações médicas, o crescente número de intervenções específicas/independentes, e o papel de viabilizar e concretizar o cumprimento de muitos elementos da prescrição médica, têm exposto a enfermagem ao mesmo risco potencial que nossos parceiros de equipe de saúde, mostrando que a situação não se restringe mais exclusivamente a categoria médica.

A iatrogenia do cuidado de enfermagem estaria relacionada a privação destes cuidados, a sua imposição ou a prestação insatisfatória deles, de forma a que viessem determinar algum transtorno, dano ou prejuízo ao bem estar do ser humano/cliente (MADALOSSO ${ }^{12}$ ). Esta situação, seria algumas vezes até conhecida e esperada, e entendida e aceita, devido ao fato de que o resultado secundário do cuidado, tivesse um caráter preponderante sobre o resultado primário. FÁVERO ${ }^{8}$ (p. 983) dialogando com esta questão de custo e benefício da ação da saúde, a descreve como fazer o mal, para evitar um mal maior.

Mas como falar de uma forma tão bela, quase poética, através da linguagem estética, de uma situação tão desagradável e perigosa como esta que assola o quotidiano da enfermagem? 
Baseada nos referenciais de Maffesoli apud POLAK $^{18} ;$ REZENDE $^{16,17}$ e CRESP $^{7}$, luto para encontrar novos caminhos para este esclarecimento, mas não de uma forma belicosa, mas de uma forma estimulante e prazerosa de descobrir.

Encontrei lá na Grécia Antiga, na sua soberba e instigante sabedoria mitológica, mais sementes para o meu entendimento. Fui ao Panteão grego buscar a graça do jogo das forças divinas, pois entendo os pensamentos míticos como fazendo parte da história do homem, como elementos poderosos, recorrentes e simbólicos, que permitem a decodificação e a compreensão do nosso quotidiano. Desta forma, a mitologia grega é tomada como uma analogia viva do viver do ser humano, ator de uma existência e de uma história.

Assim, como este olhar, é que me permiti então, penetrar na fábula mítica grega e encontrar Apolo, o mais belo dos deuses, o senhor da forma, da beleza, do vigor e da saúde que, para preservar estes ideais, concedeu a seu filho Asclépius o poder divino e supremo da cura, elegendo-o deus da medicina e dos remédios. Asclépius aprendeu com o pai a arte da poderosa cura, a tal ponto de tornar-se capaz de devolver a vida aos mortos. Por anos, através de seus oráculos, no Templo de Epidaurus, o templo das curas, exerceu o seu poder divino de vida sobre a morte.

Esta passagem mitológica grega, analogicamente nos mostra a onipotência e a onisciência que os profissionais da saúde muitas vezes têm em relação ao seu lugar e ao seu poder, frente aos clientes e aos seus males. Particularmente, com relação à profissão, como Asclépius, nós enfermeiros buscamos, através de nossos cuidados, "salvar nossos clientes" do sofrimento e da morte. Mas não podemos resolver tudo, somos meros seres humanos falíveis. Não somos deuses como Apolo e Asclépius.

O próprio Asclépius, tão poderoso, não pode evitar sua morte, mostrando que o legado da divina vida e da poderosa morte, impõe limites ao poder de cura e remediação dos males. Desta maneira, a mitologia nos mostrou que o poder de salvação de Asclépius, deixouse esvair nas brechas dos limites humanos e nos transferiu o legado de que esta força, não mais estaria no poder divino, mas no fantástico mundo da vida quotidiana, na capacidade dos cuidadores em orientarem suas ações de saúde de acordo com a realidade presente e com suas potencialidades, articuladas as visões de mundo de seus clientes.

Os profissionais de saúde, como quaisquer seres humanos, são falíveis, capazes de cometer erros; são humanos e não divinos. No entanto, como estes erros envolvem o bem estar, a integridade ou a vida de outra pessoa, à ótica social e humana, tal prejuízo é contestado. $\mathrm{O}$ nosso quotidiano nos mostra que este erro iatrogênico não representa uma raridade desaparecida. É uma situação presente e relativamente freqüente no processo de cuidar. É a sombra que nos aflige e instiga, nos persegue e impulsiona, nos aterroriza e nos mobiliza, e de quem avidamente tentamos escapar. Por mais desencorajadora e desagradável que possa parecer ser, por mais ardilosa e assustadora que se mostre, mais nos desafia e nos seduz a encontrar mecanismos de proteção e superação.

A iatrogenia do cuidado somente não é identificada com maior freqüência, pela capacidade e astúcia de alguns profissionais em se protegerem, se solidarizarem e mascararem tais situações - solidariedade orgânica -, e pela limitada capacidade de uma boa parte dos clientes de entenderem-se lesados.

A realidade crua da iatrogenia do cuidado de enfermagem se desvela para além dos desejos, aspirações e idealizações do bem fazer e, muitas vezes, acaba atrofiando ou até matando as pequenas ilusões de uma prática planejada e perfeita, quando o inesperado a corroe e as frustrações acontecem.

O que houve conosco? Onde falhamos? O que está acontecendo?

O espírito dos tempos modernos, pautado na ótica progressista, no futurismo e no finalismo, valorizando a eficiência e a competência pelo resultado produzido, impôs características à enfermagem que lhe pareciam dar segurança e domínio sobre o seu fazer, protegendo-a do risco iatrogênico. No entanto, o controle, a disciplina, a ordem, o dito perfeccionismo e a ponderação, não foram suficientes para lhe garantir esta proteção aos perigos inerentes a si própria.

Como a modernidade mostrou-se impotente para a proteção e a resolução deste e dos vários dilemas e problemas que cercavam a realidade, germinou nos horizontes da contemporaneidade um novo paradigma, de prazeres à humanidade, sem o ontem ou o amanhã, mas repleto do agora.

Vivemos hoje um período de transição, de revisão e de contestação das idéias da modernidade. O momento é de efervescência em todos na sociedade, em todas as ciências, da matéria ao espírito, do corpo ao indivíduo, da razão ao instinto, resgatando-se os mistérios, os prazeres e as inconseqüências, abrindo-se brechas na enfermagem controlada, rotinizada e teoricamente previsível.

Esta nova perspectiva que perpassa a realidade, tem se caracterizado pelo caos, pelos problemas e pelas soluções, pelas diferenças e similitudes, pela regularidade e pela imprevisibilidade, pelo usual e pela raridade, pelas estabilidades e pelas modulações, sem verdades absolutas, onde o presente, os sentimentos e a relativização se insinuam progressivamente através de um intenso vitalismo. 
Este caos, não reflete uma desestruturação ou uma desagregação social, mas um reencontro dos indivíduos pelo tribalismo. Analisando estas relações pósmodernas, deste novo cenário social, Maffesoli $\left(\mathrm{REZENDE}^{17}\right.$, p. 5) coloca que é quando existe incompletude que a relação se torna necessária.

Este novo jogar o jogo da vida requer uma nova leitura e abordagem da realidade, pautada na compreensão e na solidariedade sensível, onde se mesclam a ordem, a desordem, o prazer e a felicidade. Agora mais do que a possibilidade de serem saudáveis, os indivíduos querem é ser felizes, mesmo que isto implique em perigo para a sua condição de ter saúde. Rezende $\left(\mathrm{POLAK}^{18}\right.$, p. 74) dissecando este enfoque, expressa que (...) se a felicidade implica em ter saúde, muito mais do que ser saudável, é preciso ser feliz.

Desta maneira, como enfermeiros e seres humanos que somos, precisamos nos despojar das vestes limitadoras da modernidade, para podermos compreender esta realidade e sua gente, com novas perspectivas e novos anseios. Precisamos lançar olhares que descubram e não encubram estes novos caminhos de fazer enfermagem, rompendo com a crueza, a invisibilidade, a fragmentação e a despersonalização de nossos clientes.

Para o enfrentamento deste instigante e, algumas vezes, desconcertante mundo que se vislumbra, e melhor viver a enfermagem, instrumentos de relação são ainda mais necessários. Maffesoli (NASCIMENTO ${ }^{14}$ ) identifica estes instrumentos como categorias compreensivas de resistência. Estas são as formas de viver em mais harmonia com o outro e com o mundo. São válvulas de escape que, consciente ou inconscientemente empregadas, permitem aos seres humanos suportar as imposições que a realidade lhes apresenta. São, a solidariedade orgânica, o jogo duplo, a transgressão, a astúcia, a resistência passiva, as máscaras sociais, entre outras.

Munida destas armas, a enfermagem dispõe de recursos para mais harmoniosamente enfrentar a adversidade da iatrogenia do cuidado. Mas, ao mesmo tempo, elas não a afastam da responsabilidade moral e ética que tem em relação aos seus fazeres e ao ser humano, seu cliente.

Esta nova enfermagem tem que estar preparada para cuidar dos indivíduos deste novo tempo, que não desejam mais serem submetidos simplesmente à cura, querem ser tratados como gente, partilhar e interagir nos cuidados para alcançar um bem viver. Não aceitam mais o tão perigoso fazer para produzir, que empobrece o viver do ser humano, que não considera o preço e os sacrifícios que são impostos para serem alcançados.

Como vencer, então, a iatrogenia do cuidado de enfermagem?

Não podemos vencê-la, mas podemos preveni-la e remediá-la. Não somos infalíveis como os deuses, somos humanos e passíveis de falhas. Temos sim, é que buscar instrumentos que nos permitam a prevenção e a proteção para este problema. É necessário o desenvolvimento de mecanismos de resistência na profissão, que estimulem ainda mais a compreensão, a astúcia, a negociação e a solidariedade. É necessária a definição do estatuto da profissão e do incremento do desenvolvimento de conhecimentos próprios, que nos respaldem, nos amparem e nos protejam.

As fontes de respostas para as questões deste diálogo, estão no nosso quotidiano, basta buscá-las. O mundo da vida esta aí ao nosso redor, revitalizante e instigante. Como Milton Nascimento e Ronaldo Bastos colocam em sua música "Fé cega, faca amolada", nada mais será como antes, a fé cega se esvai e o agora é que precisa ser vivido e entendido:

Agora não pergunta mais aonde vai a estrada Agora não espero mais aquela madrugada

Vai ser, vai ser, vai ter que ser, vai ser faca amolada

O brilho cego de paixão e fé, faca amolada

Deixar a sua luz brilhar e ser muito tranqüila

Deixar o seu amor crescer e ser muito tranqüilo

Brilhar, brilhar, acontecer, brilhar, faca amolada

Irmão, irmã, irmão de fé, faca amolada

Plantar o trigo e refazer o pão de cada dia

Plantar o trigo e refazer o pão de todo o dia

Beber o vinho e renascer na luz de todo o dia

Beber o vinho e renascer na luz de cada dia

A fé, a fé, paixão e fé, a fé, faca amolada

$O$ chão, o chão, o sal da terra, o chão, faca

amolada

Deixar a sua luz brilhar no pão de todo o dia

Deixar o seu amor crescer na luz de cada dia

Vai ser, vai ser, vai ter de ser, vai ser muito tranqüilo

O brilho cego de paixão e fé, faca amolada.

Nesta analogia que inspira a enfermagem, os músicos propõem, no misto de realismo e ironia, romper com a lógica da espera (CRESPI ${ }^{7}$, p. 40) do mundo moderno que se embriaga e se ilude no renascer de cada dia. Desvela o cenário das obscurecidas esperanças de cada dia. Com a faca amolada, estes poetas cortam com esta realidade devastadora e empobrecedora da eterna prontidão do "vai ser" e do "vai ter que ser", e propõe o tempo do agora, para acontecer todo o dia.

Assim, este novo paradigma que vem sendo apresentado e tem instigado a profissão, busca suplantar as vazias noções da realidade relegadas pela modernidade, eternamente e ilusoriamente preenchidas com novas esperanças quase nunca alcançadas, cheias de dor, de 
lembranças, de verdades incompletas e não verdadeiras. Busca encontrar nos recipientes do quotidiano da vida, a essência da existência humana, repleta de possibilidades, expressas nos fatos simples e corriqueiros das histórias vividas no aqui e agora:

É sempre bom lembrar

Que um copo vazio

Está cheio de ar

É sempre bom lembrar

Que o ar sombrio de um rosto

Está cheio de um ar vazio

Vazio daquilo que no ar do copo

Ocupa um lugar

É sempre bom lembrar

Guardar de cor

Que o ar vazio de um rosto sombrio

Está cheio de dor

É sempre bom lembrar

Que um copo vazio

Está cheio de ar

Que o ar no copo

Ocupa o lugar do vinho

Que o vinho busca ocupar o lugar

Dador

Que a dor ocupa a metade

Da verdade

$A$ verdadeira natureza interior

Uma metade cheia

Uma metade vazia

Uma metade tristeza

Uma metade alegria

A magia da verdade inteira

Todo poderoso amor

É sempre bom lembrar

Que um copo vazio

Está cheio de ar.

É sempre bom lembrar, como cantam Gilberto

Gil e Chico Buarque de Holanda, que nas metades das verdades interiores de cada um, encontram-se os sentimentos e os prazeres que se imaginavam ser vazios, meras emoções sem importância e significação.

É nesta ótica da dialética da vida, que a enfermagem procura valorizar a compreensão, para além de suas verdades, para as verdades daqueles que precisam de alguém e de ajuda e, na sua dor, buscam encontrar um poderoso cuidado, que perceba que naquele aparente ser vazio ou cheio de tristezas, encontra-se alguém "cheio de ar", cheio de sentimentos a serem redescobertos e de vida.

Ao fazer enfermagem, é sempre bom lembrar que nossos clientes querem mais do que a racionalidade técnica vazia ao serem cuidados. Querem um "copo cheio de ar", querem o seu bem estar para o agora, pois de que adianta tanto sofrerem para só, quem sabe um dia, usufruírem de um benefício, talvez uma metade de alegria ou uma metade de prazer.

Ironicamente, os rígidos e controlados comportamentos de fazer enfermagem, tem se mostrado incongruentes com o esperado pela clientela e por muitos profissionais, transformando-se em verdadeiras armadilhas que a maquiagem biologicista, higienista, tecnicista e impositiva não consegue mais esconder. Revelam-se novas necessidades.

Novos horizontes se vislumbram no nosso agora, como coloca Rezende (POLAK ${ }^{18}$, p. 74): a compreensão, a disposição e a abertura para novas possibilidades, só poderá enriquecer o frágil saber da enfermagem.

Construindo e desconstruindo concepções, na medida em que avança na exploração deste novo mundo de idéias e de limites que se revelam, (re)criando saberes e articulando-os incessantemente, reestruturando suas noções, mecanismos e possibilidades de resistência e de convivência neste novo tempo, a enfermagem poderá trilhar novas possibilidades de enfrentamento do risco e da realidade iatrogênica do cuidado, através de uma nova ótica, sem renegar a razão, mas aliando e valorizando o respeito, a sensibilidade, a união e os momentos daqueles seres humanos que nela depositam a sua vida, anseios e confiança.

Ao adentrar neste exercício reflexivo e questionar como o cuidado de enfermagem acontece no mundo quotidiano, fica então incontestável a necessidade da construção de uma nova enfermagem, pautada em conhecimentos sólidos e particulares, na ética da vida, nos sentimentos e nos prazeres, na solidariedade e na resistência passiva, alicerçada no exercício da cidadania.

Estes elementos são cruciais quando se deseja afastar dos nossos caminhos os riscos, e aproximar o bem cuidar. Não é difícil perceber, mesmo para os menos atentos e preocupados, que a possibilidade da iatrogenia do cuidado de enfermagem, faz soar o alarme do perigo e da ameaça para o existir do ser humano, cliente ou profissional.

Desta forma, sem dúvida alguma, é urgentíssimo que a temática, aqui timidamente desvelada, seja colocada como um dos focos de atenção para todos aqueles profissionais enfermeiros que queiram realmente viver o fazer cuidar do ser humano.

E para concluir este primeiro encontro e diálogo com o quotidiano do cuidado de enfermagem e seus perigos, me permito expor um pensamento que estimule o repensar para a nossa profissão:

Olhe cada caminho com cuidado e atenção. Tente-o tantas vezes quantas julgar necessárias...Então, faça a si mesmo, e apenas a si mesmo, uma pergunta: possui este caminho um coração? Em caso afirmativo, o caminho é bom. Caso contrário, este caminho não possui importância alguma. (Don Juan) 


\section{NURSING IATROGENIC CARE: DIALOGUING WITH DANGER IN PROFESSIONAL QUOTIDIAN}

The study presents the conceptions and experiences of a faculty nurse, built on his quotidian of providing car and, showing, in this context, nursing iatrogenic care. Through the aesthetic language, the author presents reflections and some references of authors who work on the quotidian, characterizing nursing care and, mainly, nursing iatrogenic care within the image of modern and post-modern paradigms.

\section{IATROGENIA DEL CUIDADO DE ENFERMERIA: DIALOGANDO CON EL PELIGRO EN EL COTIDIANO PROFESIONAL}

Este artículo presenta las concepciones y experiencias de un profesor de enfermería, tejidas en su cotidiano de cuidar, $y$ desvela, en este contexto, el cuidado iatrogénico de enfermería. A través del lenguaje estético, expone sus reflexiones y algunas referencias de autores que trabajan con el cotidiano, caracterizando el cuidado de enfermería y principalmente el cuidado iatrogénico de enfermería sobre la óptica de los paradigmas modernos e pós-modernos.

TÉRMINOS CLAVES: enfermería, cuidados de enfermería, iatrogenia

\section{REFERÊNCIAS BIBLIOGRÁFICAS}

01. CIANCIARULLO, T.I. Instrumentos básicos para cuidar: um desafio para a qualidade da assistência. São Paulo: Atheneu, 1996.

02. COHEN, M.R. Medication errors. Nursing, v. 11, n. 2, p. 105, February 1981.

03. Medication errors. Nursing, v. 12, n. 11, p. 84-85, November 1982.

04. Medication errors: double check similar drug names. Nursing, v. 14, n.4, p. 24, April 1984.

05. COLLIÈRE, M.F. Cuidado invisível e mulheres invisíveis como provedoras de cuidados de saúde. International Journal of Nursing Studies, v. 23, n. 2, p. 95-112, 1986.

06. Promover a vida. Lisboa: Printipo/ Sindicato dos Enfermeiros Portugueses, 1989.

07. CRESPI, F. Les risque du quotidien. Cahiers Internationaux de Sociologie, Paris, v. 74, p. 3945, 1983.

08. FÁ VERO, F. Medicina legal. Belo Horizonte: Vila Rica, 1991.

09. ILLICH, I. A expropriação da saúde: nêmesis da medicina. Rio de Janeiro: Nova Fronteira, 1975.

10. LEININGER, M. Teoria do cuidado transcultural: diversidade e universalidade. In: SIMPÓSIO BRASILEIRO DE TEORIAS DE ENFERMAGEM (SIBRATEN), 1, Florianópolis, 1985. Anais. Florianópolis: Ed. UFSC, 1985. p. 255-276.
11. LEOPARDI, M.T. Entre a moral e a técnica: ambigüidades dos cuidados da enfermagem. Florianópolis: Ed. da UFSC, 1994.

12. MADALOSSO, A.R.M. Construindo um referencial teórico sobre a iatrogenia na prática de enfermagem. Passo Fundo/RS: 1998. Projeto de Dissertação. Mestrado Interinstitucional em Assistência de Enfermagem, da Universidade Federal de Santa Catarina/Pólo Universidade de Passo Fundo. (mimeo)

13. Nota prévia de dissertação. Construindo um referencial teórico sobre a iatrogenia na prática de enfermagem. Revista Texto \& Contexto Enfermagem/UFSC, Florianópolis, 1999. (no prelo)

14. NASCIMENTO, E.S. Noções que animam o quotidiano. In: CURSO DE QUOTIDIANO E SAÚDE - UMA ABORDAGEM SÓCIOCOMPREENSIVA. Rio Grande: FURG, nov / 1997. (mimeo)

15. PATRÍCIO, Z.M. Ser saudável na felicidade prazer. Pelotas: Ed. Universitária/UFPEL, 1996.

16. REZENDE, A.L.M. A harmonia da desordem: sofrimento e transgressão no trabalho de saúde. Revista de Enfermagem da UERJ, Rio de Janeiro, v. 3, n. 1, p. 85-92, maio 1985.

17.

Estilo estético e vida quotidiana. Texto trabalhado na Disciplina Seminário de Controvérsias, do Curso de Mestrado em Assistência de Enfermagem/UFSC, fev. 1999. (mimeo) 
18. POLAK, Y.N.S.; KALEGAL, D.R.G.; JOUCLAS, M.G. Saúde do adulto: um enfoque multidisciplinar. Curitiba: Pinha, 1997.

19. SANTOS, S.M.A. A especificidade da enfermagem na equipe interdisciplinar. Revista Texto $\&$ Contexto Enfermagem/UFSC, Florianópolis, v. 6, n. 2, p. 156-161, maio/1997.
20. WALDOW, V.B.; LOPES, M.J.M.; MEYER, D.E. Maneiras de cuidar/maneiras de ensinar: a enfermagem entre a escola e a prática profissional. Porto Alegre: Artes Médicas, 1995.

21. WAIDMAN, M.A.P. Enfermagem: cuidar ou assistir? Uma reflexão sobre estes temas. In: ENCONTRO BRASILEIRO DE CUIDADO E CONFORTO EM ENFERMAGEM (EMBRACE), 1, Itapema, 1996. Anais. Florianópolis: Ed. UFSC, 1996 p. 31. 